\title{
Predictions of seasonal natural mortality rates in a copepod population using life-history theory
}

\author{
R. A. Myers ${ }^{1}$ and J. A. Runge ${ }^{2}$ \\ 1 Department of Biology and ${ }^{2}$ Department of Oceanography, Dalhousie University, Halifax, Nova Scotia, Canada B3H 4J1
}

\begin{abstract}
We use inverse optimization techniques and data from Landry (1978) to predict natural mortality rates in a population of the marine, planktonic copepod Acartia clausii. Predicted mortality rates are those that make the observed seasonal pattern of life-history characteristics evolutionarily stable. Our predictions closely approximate the rates observed by Landry. The results imply (1) that the inverse relationship between adult body size and temperature in $A$. clausii (also widely observed in other copepods and poikilotherms) is consistent with the hypothesis that it is an evolutionary adaptation to a seasonal environment, and (2) that demographic parameters, such as natural mortality rates, can be usefully estimated from life-history theory.
\end{abstract}

\section{INTRODUCTION}

We present a new approach for estimating natural mortality rates in zooplankton populations based on the assumption that observed life-histories are evolutionarily stable (Maynard Smith, 1974). A population is evolutionarily stable, with respect to a phenotype or set of phenotypes, if a rare gene introduced into the population will always be eliminated when the phenotype of its carriers differs from the population mean (Charlesworth, 1980). The particular phenotypic characteristic that we assume to be evolutionarily stable is size at maturity. In a copepod size at maturity represents the size at which a change in energy allocation from growth to reproduction occurs and may be viewed as the solution to a control problem. We use inverse optimization techniques to determine the very restricted range of natural mortality rates for which an observed size at maturity is evolutionarily stable.

The size at maturity of copepod species, and of many other poikilotherms, is commonly observed to be inversely related to temperature (Konstantinov, 1958; Deevey, 1960; McLaren, 1963; Precht et al., 1973; Culver, 1980; Nelson, 1980). Physiological studies provide an understanding of the effects of temperature and food availability on growth rate and developmental time, which determine final body size (e.g. Vidal, 1980). Our approach provides a framework for determining whether observed patterns of growth and reproduction, such as the commonly observed pattern of decreased size at maturity at higher temperatures, are consistent with hypotheses of evolutionarily adaptive responses to a changing environment. This is a problem in life-history theory, a review of which was given by Charlesworth (1980).

\section{MODEL FORMULATION}

In a density-independent population, the evolutionarily stable life-history will be the survivorship and reproduction schedules, $\mathrm{l}_{\mathrm{x}}$ and $\mathrm{m}_{\mathrm{x}}$ (where $\mathrm{x}$ is age in $d$ ), which maximize the intrinsic rate of increase, $r$, for the population (Charlesworth and León, 1976). That is, for any other feasible survivorship and reproductive schedule, $\mathrm{l}_{\mathrm{x}}{ }^{\prime}$ and $\mathrm{m}_{\mathrm{x}}{ }^{\prime}$ '

$$
\sum_{x=1}^{T} \exp (-\Gamma x) l_{x}^{\prime} m_{x}^{\prime}<\sum_{x=1}^{T} \exp (-r x) l_{x} m_{x}=1,
$$

where $\mathrm{T}=$ maximum lifespan.

If $\mathrm{r}$ and the growth and reproductive schedules are known, the survivorship schedule (and thus mortality rates) can be estimated from the maximization process implied by Eq. 1 (Myers and Doyle, 1983). Here we investigate the use of life-history theory to predict the mean observed life-history. For a variety of reasons (e.g. Lande, 1976, 1979; Doyle and Myers, 1982) there will be genotypic and phenotypic variability about the mean life history that we shall not be concerned with here. 
Landry's (1978) study of Acartia clausii in Jakle's Lagoon (San Juan Island, Washington, USA) may be the most comprehensive published demographic analysis of a marine planktonic population. Landry determined stage-specific mortality rates from a detailed analysis of population abundance, age structure, and duration of developmental stages over a 2-yr period. Except for age at senescence, all life-history characteristics pertain to the population in the lagoon. Comparisons between observed mortality rates and predictions from life-history theory are therefore warranted.

The analysis for Acartia clausii is straightforward. The number of female zygotes released at age $x+1$ is

$$
\mathrm{m}_{\mathrm{x}+1}=\mathrm{C}_{\mathrm{e}} \mathrm{u}_{\mathrm{x}} \mathrm{f}\left(\mathrm{w}_{\mathrm{x}}\right)
$$

where $w_{x}=$ weight at age $\mathrm{x} ; \mathrm{f}\left(\mathrm{w}_{\mathrm{x}}\right)=$ energy available for growth and reproduction for an individual of

\section{ANALYSIS}

\section{Mortality independent of size}

The predicted natural mortality rate is the mortality needed to make the observed weight at maturity $\left(\mathrm{W}_{\mathrm{M}}{ }^{*}\right)$ evolutionarily stable. The first step in the inverse optimization procedure is to determine the evolutionarily stable weight at sexual maturity as a function of survivorship schedule, $W_{M}\left(l_{1}, l_{2}, \ldots, l_{\Upsilon}\right)$, from the maximization

$$
\begin{aligned}
& \max \sum_{x=1}^{T} \exp (-r x) l_{x} u_{x-1} f\left(w_{x-1}\right) \\
& u_{x} \\
& x=1,2, \ldots, T-1
\end{aligned}
$$

where the weights are constrained by Eq. 3. Predicted survivorship schedules (and thus mortality regimes)

Table 1. Acartia clausii. Life history parameters and calculated mortality rates. Developmental temperatures (t: ${ }^{\circ} \mathrm{C}$ ) are weighted means for cohorts, calculated from Landry (1976, Table 7 or Appendix). Weight at maturity ( $\mathrm{W}_{\mathrm{m}}$ : $\mu \mathrm{g}$ C) determined from relationship between dry weight and cephalothorax length (Landry, 1978; Table 6), assuming a carbon/dry weight ratio of 0.4 . Growth rate $(\alpha)$ solved from Eq. (3), egg weight $=0.035 \mu \mathrm{g} \mathrm{C}$ (Landry, 1978), and development time from egg to adult, is a

\begin{tabular}{|c|c|c|c|c|c|c|c|c|c|c|c|c|c|c|c|}
\hline & $\begin{array}{l}15 \\
\text { Apr } \\
\text { (I) }\end{array}$ & $\begin{array}{c}2 \\
\text { May } \\
\text { (II) }\end{array}$ & $\begin{array}{c}2 \\
\text { Jun } \\
\text { (III) }\end{array}$ & $\begin{array}{c}2 \\
\text { Jul } \\
\text { (IV) }\end{array}$ & $\begin{array}{c}2 \\
\text { Aug } \\
\text { (V) }\end{array}$ & $\begin{array}{c}12 \\
\text { Sep }\end{array}$ & $\begin{array}{l}25 \\
\text { Oct }\end{array}$ & $\begin{array}{c}12 \\
\text { Feb }\end{array}$ & $\begin{array}{c}12 \\
\text { Mar }\end{array}$ & $\begin{array}{c}25 \\
\text { Apr } \\
\text { (VII) }\end{array}$ & $\begin{array}{c}30 \\
\text { May } \\
\text { (VIII) }\end{array}$ & $\begin{array}{l}25 \\
\text { Jun } \\
\text { (IX) }\end{array}$ & $\begin{array}{l}25 \\
\text { Jul } \\
(X)\end{array}$ & $\begin{array}{c}15 \\
\text { Aug } \\
\text { (XI) }\end{array}$ & $\begin{array}{c}7 \\
\text { Sep }\end{array}$ \\
\hline$t$ & 11.5 & 14.0 & 16.5 & 18.5 & 19.5 & 17.5 & 12.0 & 6.0 & 6.5 & 8.5 & 12.5 & 14.5 & 15.5 & 17.5 & 19.0 \\
\hline$\alpha$ & 0.171 & 0.196 & 0.226 & 0.259 & 0.280 & 0.237 & 0.150 & 0.080 & 0.090 & 0.110 & 0.166 & 0.191 & 0.206 & 0.244 & 0.267 \\
\hline$W_{m}$ & 2.1 & 1.5 & 1.1 & 1.1 & 1.1 & 1.05 & 1.5 & 2.6 & 2.3 & 1.5 & 1.4 & 1.2 & 1.2 & 1.2 & 1.2 \\
\hline$T$ & 70 & 55 & 49 & 43 & 41 & 48 & 69 & 128 & 113 & 100 & 65 & 56 & 51 & 47 & 43 \\
\hline$\tau$ & 0.011 & 0.012 & 0.002 & -0.005 & -0.035 & -0.035 & 0 & 0.040 & 0.022 & 0.011 & 0 & -0.010 & -0.035 & -0.135 & -0.035 \\
\hline
\end{tabular}
function of temperature (Landry, 1978; Table 1). Age at senescence ( $T$ : days) is the sum of development time and maximum adult longevity (from Uye, 1981; Fig. 3). Instantaneous population growth rate ( $\left.\mathrm{r}: \mathrm{d}^{-1}\right)$ was obtained by differentiating a cubic spline

function (Boor, 1978) fit to data on seasonal abundance of developmental stages, all years combined (Landry, 1978; Fig. 4)

weight $w_{x i} u_{x}=$ proportion of that energy devoted to reproduction $\left(O \leq \mathrm{u}_{\mathrm{x}} \leq 1\right)$. Copepods do not molt after reaching sexual maturity, and it is a reasonable assumption that the function $\mathrm{u}_{\mathrm{x}}$ in $A$. clausii is either zero or 1 (Steele and Mullin, 1977). $C_{e}$ is a constant for converting growth into egg production. Since weightspecific growth rate appears to be equivalent to the weight-specific egg production rate (Sekiguchi et al., 1980), $C_{e}$ is simply the proportion of zygotes destined to become females divided by the average weight of an egg. Growth in A. clausii is assumed to be a linear function of weight (Miller et al., 1977; Landry, 1978) and is described by

$$
w_{x+1}=w_{x}+\left(1-u_{x}\right) f\left(w_{x}\right)
$$

where $f\left(w_{x}\right)=\alpha w_{x}$. The growth coefficient $(\alpha)$ was calculated from development time as a function of temperature (determined by Landry), female body weights, and mean egg weight (Table 1). are determined from the minimization of $\mid W_{M}\left(l_{1}\right.$, $\mathrm{l}_{2}, \ldots \mathrm{l}_{\mathrm{T}}$ ) $-\mathrm{W}_{\mathrm{M}} \cdot 1$ using a Fibonacci search (Wilde and Beightler, 1967). We assumed initially that mortality was constant for all developmental stages. The mortality predictions closely match the seasonal pattern of mortality observed by Landry (Fig. 1 a; see Table 2 for the variability of Landry's mortality data).

\section{Size dependent mortality}

Any estimate of natural mortality should result in a survivorship schedule that conforms to Lotka's equation $\left(\sum_{x} \exp (-\Gamma x) l_{x} m_{x}=1\right)$ for observed rates of increase r. Although the summation may not be precisely equal to one because of non-equilibrium age structure, it should not be consistently biased. Our mortality predictions, modified by including Landry's observation that the average combined egg and Nauplius I mortal- 


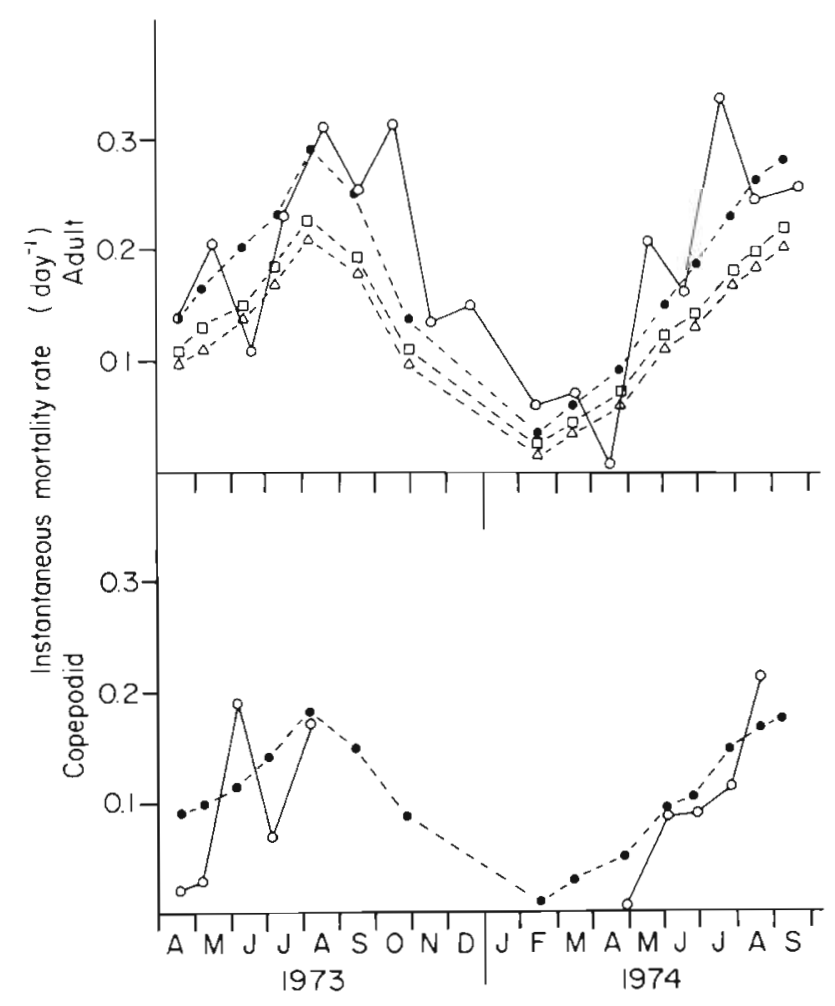

Fig. 1. Acartia clausii. Upper: observed (open circles; Landry, 1978) vs. predicted adult female instantaneous mortality $\left(\right.$ day $\left.^{-1}\right)$ in a population, Jakle's Lagoon, San Juan Island. Predicted mortality (closed circles) assuming that mortality is constant over all developmental stages; predictions assuming weight-specific mortality of the form given by Eq. 5 with $\theta$ equal to 0.5 (squares) and $\theta$ equal to 2 (triangles) Lower: observed lopen circles) vs. predicted (closed circles) copepodid mortality for same population. Observed values are medians of mortality rates determined by Landry for stages nauplius VI to copepodid IV Predicted values are calculated for copepodid $\mathrm{II}_{\text {; }}$ effects of degree of weightspecific mortality for $0.5 \leq \theta \leq 2$ too small to show. (Note that finite mortality rates calculated from the model are converted to instantaneous rates to facilitate comparison with Landry's data)

ity was 0.8 , resulted in a summation less than 0.3 for each of the 15 cohorts. That is, with the observed egg and Nauplius I mortality and the predicted constant mortality, the population could not maintain itself. Some form of age (or body size) dependent mortality can resolve this dilemma. We assumed the functional form

$$
M_{x}=M_{b}+\gamma w_{x}{ }^{\theta}
$$

where $\mathrm{M}_{\mathrm{x}}=$ mortality rate at age $\mathrm{x} ; \mathrm{M}_{\mathrm{b}}=$ mortality rate independent ${ }_{x-1}$ of body weight. Survivorship schedules $\left(l_{\mathrm{x}}=\prod_{\mathrm{y}=1}\left(1-\mathrm{M}_{\mathrm{y}}\right)\right)$ from (5) were substituted into (4) and $\gamma$, the weight specific mortality rate, was determined for a range of $\mathrm{M}_{\mathrm{b}}$ 's and $\theta$ 's by the inverse optimization technique described previously. Predictions of adult mortality rates using this mortality func-
Table 2. Acartia clausii. Medians, means, standard errors (SE) and numbers of observations ( $\mathrm{n}$ ) for observed monthly mortality rates. Data obtained from Landry (1976; Fig. 35) and Landry (1978; Fig. 22)

\begin{tabular}{|llllr|}
\hline Month & Median & Mean & S.E. & $\mathrm{n}$ \\
\hline Apr & 0.14 & 0.03 & 0.056 & 8 \\
May & 0.205 & 0.20 & 0.057 & 7 \\
Jun & 0.11 & 0.07 & 0.071 & 8 \\
Jul & 0.23 & 0.17 & 0.0169 & 10 \\
Aug & 0.31 & 0.30 & 0.099 & 11 \\
Sep & 0.255 & 0.28 & 0.113 & 5 \\
Oct & 0.31 & 0.20 & 0.098 & 3 \\
Nov & 0.13 & 0.13 & 0.09 & 2 \\
Dec & 0.15 & 0.15 & - & 1 \\
Feb & 0.06 & 0.06 & 0.011 & 3 \\
Mar & 0.07 & 0.07 & - & 1 \\
Apr & 0.01 & 0.01 & 0.094 & 2 \\
May & 0.205 & 0.20 & 0.057 & 4 \\
Jun & 0.16 & 0.15 & 0.155 & 5 \\
Jul & 0.34 & 0.23 & 0.061 & 8 \\
Aug & 0.24 & 0.30 & 0.074 & 9 \\
Sep & 0.25 & 0.25 & 0.355 & 2 \\
\hline
\end{tabular}

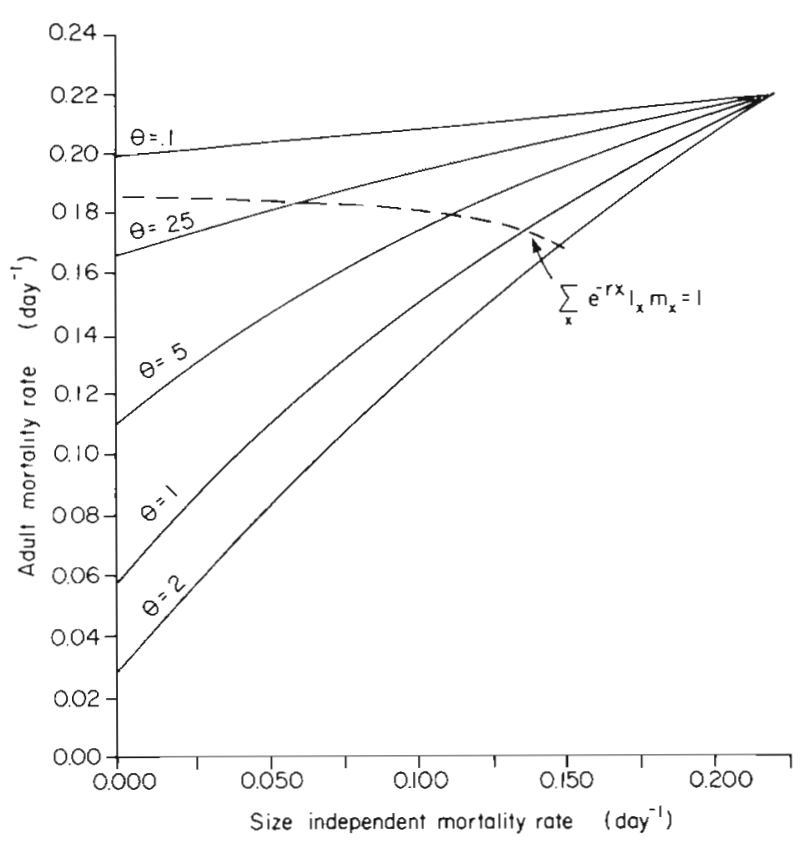

Fig. 2. Acartia clausii. Effects of weight-specific finite mortality rate on predicted adult mortality (data for Aug. 1973 cohort) assuming mortality is $M_{b}+\gamma w_{x}{ }^{\theta}$ (Eq. 5), where $M_{b}$ is the mortality independent of size, $\gamma$ is determined by an inverse optimization procedure using Eq. 3 , and $\theta$ is a power term. Dotted line: adult mortalities corresponding to

$$
\sum_{x}(\exp -\Gamma x) \mathbf{l}_{x} m_{x}=1
$$

tion are illustrated for 1 cohort in Fig. 2. The revised estimates of adult mortality underestimate the observed mortality rates (Sign test; $P<.05$ ) but the trend follows the observations (Fig. 1 a).

The prediction of weight dependent mortality 
requires that, for Acartia clausii in Jakle's Lagoon, mortality rates must increase with body size; if $\gamma$ was negative (mortality decreases with increasing size), then the summation of $\exp (-\Gamma x) l_{x} m_{x}$ would be even less than that derived when assuming constant mortality. This result is consistent with Landry's conclusion that a visual predator, the stickleback Gasterosteus aculeatus, was primarily responsible for the summer increase in mortality rates. Our predictions of copepodid mortality rates are lower than the adult values and are consistent with the observed seasonal pattern (Fig. 1 b).

\section{SOURCES OF ERROR}

\section{Population may not be evolutionarily stable}

The primary requirement for the use of this technique is that the population under study is evolutionarily stable with respect to its environment. The estimated mortality rate is not the mortality in any year, but may be viewed as a weighted average of past environments that the animal has experienced.

Although the life history of Acartia clausii in Jakle's Lagoon may not have reached an evolutionarily stable strategy, the similarity between the predicted and observed mortalities indicate that the population's life history is approximately evolutionarily stable. Since the lagoon is at least partially self-contained, genetic changes in the life history of $A$. clausii may have occurred relatively rapidly. The possibility of rapid life history adaptation is supported by the discovery of significant additive genetic variability and rapid genetic change in life-history traits in another crustacean population (Doyle and Hunte, 1981).

\section{Density dependence}

Any real population will probably be between the 2 cases of density independent and density dependent population regulation. In our analysis, we estimate the rate at which Acartia clausii was actually growing in the field. In summer, however, growth rates of field individuals measured by Landry (1978) during this period were less than laboratory estimates under optimal conditions, suggesting food limitation. There is also a possibility of an increase in naupliar mortality at high densities in $A$. clausii populations (Landry, 1978; Johnson, 1981). Even for the density dependent case, Charlesworth and León (1976) have shown that the evolutionarily stable life history is the solution to a maximization problem. Letting survivorship and fecundity be functions of density, $N$, they showed that the evolutionarily stable life history corresponded to the $1_{x}(N)$ and $m_{x}(N)$ schedule that maximized $N$. That is, for any other schedule, $l_{x}{ }^{\prime}(N)$ and $m_{x}{ }^{\prime}(N)$, at equilibrium,

$$
\sum_{x} l_{x}^{\prime}(N) m_{x}^{\prime}(N)<\sum_{x} l_{x}(N) m_{x}(N)=1 .
$$

However, for an opportunistic species such as Acartia clausii the density independent model seems to be more appropriate. Even assuming density independence for a density dependent population, the estimate of instantaneous mortality rate will be in error less than the value of $r$, the population growth rate.

\section{Resting eggs}

Resting eggs would change the calculation of sizespecific mortality because the demographic equation would require a time lag term. Resting eggs produced in one season and hatching in another would cause the summation of $\exp (-\mathrm{rx}) \mathrm{l}_{\mathbf{x}} \mathrm{m}_{\mathrm{x}}$ to be lower and higher, respectively. Since the existence of resting eggs would not cause a systematic decrease in the summation, they would have only a minor effect on the predictions.

\section{Errors in parameter estimation}

We examined the sensitivity of the analysis to errors in estimation of growth rates and of the age at senescence (maximum lifespan). Two alternative estimates of growth rates were calculated for each mortality

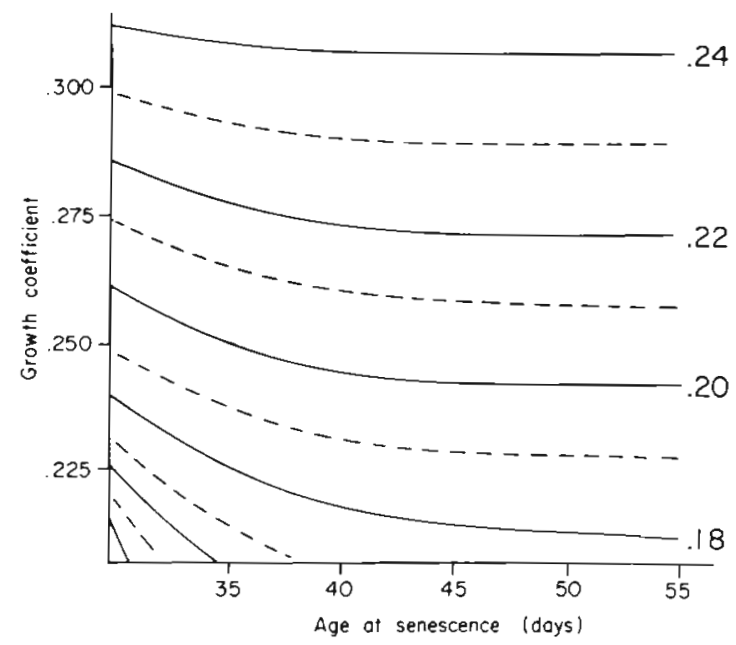

Fig. 3. Acartia clausii. Effect of errors in estimation of growth rate $(\alpha)$ and age at senescence (T) on the predicted finite mortality rate (data for July 1973; best estimates for this date are $\alpha=.259$ and $T=43 \mathrm{~d}$ ). Mortality contour lines computed assuming constant mortality in all developmental stages. There is similar sensitivity for estimation errors of $\alpha$ and $T$ if weight-specific mortality is assumed 
prediction using the upper and lower $95 \%$ confidence intervals for adult body size from Landry (1978). For the data from July 1973 these 2 growth rates ( $\alpha=.2657$ and .2505 ) resulted in finite mortality estimates of 215 and .205 (Fig. 3). Sensitivity to age at senescence was examined using alternative estimates from Landry (1978) and Sekiguchi et al. (1980). In all cases, predictions of mortality rates were altered by less than $5 \%$. The mortality estimates are more sensitive to errors in estimation of growth rates than to age at senescence (Fig. 3).

There is also the possibility of systematic errors in the estimation of parameters such as growth rate. For example, a higher conversion factor for adult length into carbon weight or a lower egg to NII mortality would raise each of the mortality predictions.

\section{DISCUSSION}

The model successfully predicted the seasonal trend in mortality rates, whether mortality rates were assumed to be constant or size (weight) dependent. The latter assumption is the more realistic case, but it resulted in an underestimate (assuming no systematic errors) of observed values (Fig. 1a). However, this underestimate did not occur in predictions of copepodid mortalities (Fig. 1 b). The underestimation of adult female mortalities may be due to another source, visibility of oocytes, which would make females more vulnerable to visual predators (Johnson, 1981). There is no quantitative data on reproductive visibility and predation to test this hypothesis for Acartia clausii, so we were unable to include this factor in the model.

The observed changes in mortality rates are sufficient to make the observed temperature-dependent size at maturity consistent with the hypothesis that the relationship of adult body size and temperature (McLaren, 1966) is adaptive. Growth rates of Acartia clausii in Jakle's Lagoon increase with temperature, despite the possibility of food limitation during the summer discussed earlier. If mortality rates did not substantially increase during the summer, the model predicts that, given the observed growth rates, female body sizes would be larger in the summer, not smaller as observed. This implies that the relationship between development time and temperature is not an uncontrollable consequence of fundamental thermodynamic laws. Two other copepod populations, both species of Acartia clausii (Johnson, 1981; Uye, 1982), have been analyzed using an approach similar to Landry's; both show considerable seasonal variation in adult mortality rates. These mortality patterns correlate with changes in temperature and appear to be the conse- quence of seasonal changes in predator numerical and feeding functional responses.

The use of temperature as a regulator of adult body size may be a general phenomenon in species whose lifespan is short relative to seasonal temperature fluctuations. In those cases where the inverse relationship is observed, and where individual growth rates increase with temperature, mortality rates should also increase with temperature, given the assumptions of the model. The decrease in age of senescence with temperature in poikilotherms (Shaw and Bercaw, 1962) is a counteracting factor, but the model is more sensitive to changes in growth rate than to age at senescence (Fig. 3).

Knowledge of mortality rates of a natural population is important for understanding ecological processes and for the rational management of exploited populations (Beverton and Holt, 1957). However, mortality is often difficult or impossible to measure, whereas data on growth and reproduction may be obtained more readily. Our analysis supports the use of life-history theory to estimate natural mortality in these situations (Myers and Doyle, 1983).

Acknowledgements. We thank C. J. Corkett, R. W. Doyle, M. R. Landry, I. A. McLaren, S. Pearre and G. Rosenberg for comments. Financial support provided by a Dalhousie Fellowship (RAM), a Killam Postdoctoral Fellowship (JAR), and NSERC grants to R. W. Doyle and C. M. Boyd.

\section{LITERATURE CITED}

Beverton, R. J. H., Holt, S. J. (1957). On the dynamics of exploited fish populations. Fish. Invest., Lond. (Ser. 2) 19: $1-577$

Boor, C. de (1978). A practical guide to splines. SpringerVerlag. New York

Charlesworth, B. (1980). Evolution in age-structured populations. Cambridge University Press

Charlesworth, B., León, J. A. (1976). The relation of reproductive effort to age. Am. Nat. 110: 449-459

Culver, D. (1980). Seasonal variation in the sizes at birth and at first reproduction in Cladocera. In: Kerfoot, W. C. (ed.) Evolution and ecology of zooplankton communities. University Press of New England, Hanover, p. 358-366

Deevey, G. B. (1960). Relative effects of temperature and food on seasonal variation in length of marine copepods in some eastern American and western European waters. Bull. Bingham oceanogr. Coll. 17: 54-84

Doyle, R. W., Hunte, W. (1981). Demography of an estuarine amphipod (Gammarus lawrencianus) experimentally selected for high ' $r$ ' : a model of the genetic effects of environmental change. Can. J. Fish. aquat. Sci. 38: $1120-1127$

Doyle, R. W., Myers, R. A. (1982). The measurement of the direct and indirect intensities of natural selection. In: Dingle, H., Hegmann, J. P. (eds.) Evolution and genetics of life histories. Springer-Verlag, New York, p. 157-176

Johnson, J. K. (1981). Population dynamics and cohort persistence of Acartia californiensis (Copepoda: Calanoida) in 
Yaquina Bay, Oregon. Ph. D. thesis, Oregon State University

Konstantinov, A. S. (1958). The effect of temperature on the growth rate and development of chironomid larvae. Dokl. Biol. Sciences 120 (6): 1362. Trans. AIBS 120: 506-509

Lande, R. (1976). The maintenance of genetic variability by mutation in a polygenic character with linked loci. Genet. Res. 26: 221-234

Lande, R. (1979). Quantitative genetic analysis of multivariate evolution, applied to brain:body allometry. Evolution 33: 402-416

Landry, M. R. (1976). Population dynamics of a planktonic marine copepod, Acartia clausii, in a small temperate lagoon on San Juan Island; Washington. Ph. D. thesis, University of Washington, USA

Landry, M. R. (1978). Population dynamics and production of a planktonic marine copepod, Acartia clausii, in a small temperate lagoon on San Juan Island, Washington. Revue ges. Hydrobiol. 63: 77-119

Maynard Smith, J. (1974). The theory of games and the evolution of animal conflict. J. theor. Biol. 47: 209-221

McLaren, I. A. (1963). Effects of temperature on growth of zooplankton and the adaptive value of vertical migration. J. Fish. Res. Bd Can. 20: 685-727

McLaren, I. A. (1966). Adaptive significance of large size and long life of the Chaetognath Sagitta elegans in the arctic Ecology 47: 852-855

Miller, C. B., Johnson, J. K., Heinle, D. R. (1977). Growth rules in the marine copepod genus Acartia. Limnol. Oceanogr 22: $326-335$

Myers, R. A., Doyle, R. W. (1983). Predicting natural mortality rates and reproduction-mortality tradeoffs from fish life history data. Can. J. Fish. aquat. Sci. (in press)

Nelson, W G. (1980). Reproductive patterns of gammaridean amphipods. Sarsia 65: 61-71

Precht, H., Christopherson, J., Hensel, H., Larcher, W. (eds.) (1973). Temperature and life. Springer-Verlag, New York

Sekiguchi, H., McLaren, I. A., Corkett, C. J. (1980). Relationships between rates of growth and reproduction in the copepod Acartia clausii hudsonica. Mar. Biol. 58: 133-138

Shaw, R. F., Bercaw, B. L. (1962). Temperature and life-span in poikilothermous animals. Nature, Lond. 196: 454-457

Steele, J. H., Mullin, M. (1977). Zooplankton dynamics. In: Goldberg, E. (ed.) The seas, Vol. VI, ch. 22. Wiley, New York, p. 857-890

Uye, S. I. (1981). Fecundity studies of neritic calanoid copepods Acartia clausii Giesbrecht and A. steueri Smirnov: a simple empirical model of daily egg productions. J. exp. mar Biol. Ecol. 50: 255-271

Uye, S. I. (1982). Population dynamics and production of Acartia clausii. J exp mar Biol. Ecol. 57: 55-83

Vidal, J. (1980). Physioecology of zooplankton. I. Effects of phytoplankton concentration, temperature, and body size on the growth rate of Calanus pacificus and Pseudocalanus sp. Mar Biol 56: 111-134

Wilde, D. J., Beightler, C. S. (1967). Foundations of optimization. Prentice-Hall, Englewood Cliffs, New Jersey 